\title{
XXXIII. On the existence and effects of allotropism in the constituents elements of living beings
}

\section{John William Draper M.D.}

To cite this article: John William Draper M.D. (1849) XXXIII. On the existence and effects of allotropism in the constituents elements of living beings, Philosophical Magazine Series 3 , 34:229, 241-246, DOI: 10.1080/14786444908646224

To link to this article: http://dx.doi.org/10.1080/14786444908646224

曲 Published online: 30 Apr 2009.

Submit your article to this journal $₫$

Џ Article views: 1

Q View related articles 5 
THE

LONDON, EDINBURGH AND DUBLIN

PHILOSOPHICAL MAGAZINE

A N D

JOURNAL OF SCIENCE.

[THIRD SERIES.]

APRIL 1849.

XXXIII. On the Existence and Effects of Allotropism in the constituent elements of Living Beings. By JoHn WiLliam Draper, M.D., Professor of Chemistry in the University of New York*.

T' has been completely established for the majority of ele1 mentary substances, that there are several forms under which each may occur; forms which differ entirely both in their physical and chemical relations.

Thus, in the case of carbon, many such forms are known. To three of them M. Berzelius has directed attention:-1st, ordinary charcoal; 2nd, plumbago; 3rd, diamond. They are three distinct modifications of the same element. They differ in specific gravity, in specific heat, and in conducting power, both for electricity and caloric. In their relations to light, the first perfectly absorbs it and is black; the second reflects it like a metal; the third is transparent like glass. When crystallized, plumbago and diamond do not belong to the same system : their chemical relations are also strikingly different. Charcoal takes fire with facility, and some varieties of it are even spontaneously combustible in the air ; but crucibles and furnaces are made of plumbago because of its incombustibility; and the diamond with difficulty is set on fire in pure oxygen gas.

It seems immaterial to what class elementary bodies belong, whether electro-negative or positive: they present analogous results. Silicon, sulphur, selenium, phosphorus, titanium, chromium, uranium, tin, iridium, osmium, copper, nickel, cobalt, iron, oxygen, chlorine, are cases in point; and the instances which appear as exceptions are rapidly diminishing in number.

* Communicated by the Author.

Phil. Mag. S. 3. Vol. 34. No. 229. April 1849.

$\mathbf{R}$ 


\subsection{Prof. Draper on the Existence and Effects of Allotropism}

Asis well known, to these singular modifications M. Berzelius gave the designation of allotropic forms, and the whole phænomenon passes conveniently under the designation of allotropism. He shows that the peculiarity assumed is often of such a persistent nature that it is not lost, even though the substance affected should go into combination with others. Thus there are two forms of silicon; one combustible, and the other remarkably incombustible. Each, by uniting with oxygen, gives rise to a silicic acid; the acid in one case being soluble in water and in hydrochloric acid, and in the other the reverse. And in like manner, metallic arsenic, which exhibits the same duality of condition, gives rise to two different arsenious acids. Of phosphorus there are at least two modifications; and accordingly we have two compounds of that body with hydrogen, one of which is spontaneously inflammable, and the other not; and at least two oxygen acids, the monobasic and tribasic, in which the essential difference rests in the state of the phosphorus they contain.

It is to be remarked, that, so far as observation extends, the most common cause of producing these singular differences is the action of that class of agents which we term imponderable substances. In very many cases change of temperature brings abont allotropic change; in others it is the agency of light, as in chlorine and phosphorus; and again, in others, association with foreign bodies, which apparently establish new voltaic relations. Heat, light and electricity seem to be the general modifying agents.

Mi. Berzelius, following the suggestion of M. Frankenheim, proposes a nomenclature for pointing out the peculiar form referred to in any special case. It depends on the use of Greek letters. Thus we have the three forms of carbon just alluded to, designated on these principles by $\mathrm{C}_{\alpha}, \mathrm{C} \beta, \mathrm{C}_{\gamma}$. But in a paper which I published in this Journal on the allotropism of chlorine (Nov. 1845, p. 327), it is remarked that we may often with greater convenience use the simple expressions "active" and "passive." Thus active chlorine is that which will decompose water in the dark, passive chlorine failing to do so. In this paper the same expressions will be eniployed.

Hitherto allotropism has only been considered as affecting inorganic states of matter, but its influence can be plainly traced in the far more interesting case of organic beings; and, when placed in a proper point of view, yields a remarkable explanation of some of the most obscure but important facts in physiology and pathology. These explanations I propose now to point out. 
In the Philosophical Magazine (March 1846, p. 178) there is a paper by me explanatory of the causes of the circulation of the blood in the capillary vessels. It is merely an abridgement of a lecture which for eight years past has been delivered in this university. The doctrine there set forth has been generally received in America, and introduced into some of the standard works on physiology published in England. The principle on which it essentially depends, and which has been abundantly confirmed by direct experiment, is briefly thisthat if there be two fluids occupying a capillary tube, or a porous structure of any kind, under the condition that one of them has a stronger chemical affinity for the substance of that tube or structure than the other, a movement of the liquids will at once ensue, that which has the stronger affinity driving the other before it. On this principle a clear account of the systemic circulation of animals may be given; for the arterial blood, an oxidizing liquid, having a stronger affinity for the soft tissues with which it is in contact than the venous blood, the affinities of which have been satisfied and therefore no longer exist, necessarily exerts such a pressure that motion must ensue, the arterial blood forcing the venous before it.

An application of the same principles shows that in the pulmonary circulation the motions must necessarily be in the opposite direction, or from the venous to the arterial side, as is actually the case. It also explains clearly the conditions of the portal circulation, in which the direct action of the heart could hardly be expected to be felt. With the generality which ought to belong to a true theory, it meets all the cases which occur in the lower orders of animal life, such as the greater circulation in fishes, in which there is no systemic heart; the movements which take place in the vascular system of insects; and even the extreme case of the rise and descent of sap in plants.

In this doctrine everything depends on the relationship between the nutritive fluid, or blood, and the solid parts with which it is brought in contact; and whatever changes that relationship must impress a corresponding change on the circulation itself.

From experiments which I made some time ago, I have been led to suppose that the arterialization of the blood, as it takes place on the cell-walls of the lungs, bears a strong analogy to the oxidation of white indigo. The loose hold which the colouring matter of the blood retains on the oxygen, coupled but not combined with it, is not unlike what is witnessed in other nitrogenized colouring matters, such as indigo, which oxidizes and deoxidizes with the utmost facility. Charged 


\section{Prof. Draper on the Existence and Effects of Allotropism}

with the oxygen it has thus obtained, the arterial blood passes to all parts of the system; and now arises that striking but all-important physiological fact, that it does not attack indiscriminately all those parts of the soft solids which it first encounters, but proceeding in a measured way, exerts its action on such particles alone as have become effete, and accomplishing the great process of interstitial death, resolves those particles into other forms, so that they can be eliminated from the system by the lungs, the kidneys, and the skin.

Now why is it that things proceed in this way? What is it that regulates this interstitial death? Why is one atom preserved and another surrendered?

It is upon these obscure points that the recent discoveries in allotropism shed a flood of light.

The three leading neutral nitrogenized bodies, fibrine, albumen and caseine, are characterised by exhibiting allotropism in a most remarkable degree, and that in a double sense. 1st. Though so different from one another in their physical and chemical relations, it is admitted on all hands that they are mutually convertible; the albumen of the egg, during incubation, gives rise to fibrine and other allied bodies; from caseine, in the milk with which the young mammalia are nourished, the albuminous and fibrinous constituents of their systems arise; the nurse fed on fibrine and albumen secretes caseine from the mammary gland. Indeed there is no more reason to regard these three bodies as essentially distinct substances, than there is to apply the same conclusion to charcoal, plumbago and diamond. Between the two cases there is the most complete analogy; and if charconl, plumbago and diamond, are merely allotropic forms of one substance, the same holds good for fibrine, albumen and caseine. But 2nd, each of these three compounds betrays a disposition under trivial causes to assume new forms; as with silicic acid so with fibrine, there are two varieties, one soluble in water, the other not. A difference of a few degrees of heat turns transparent albumen into the porcellanous variety, and analogous observations might be made respecting caseine.

It may therefore be asserted that these proteine bodies exhibit a propensity to allotropism in a far more remarkable manner than any other substances known; not only passing indiscriminately into one another, but also exhibiting special variations under the influence of the most trivial causes.

And now we may recall the fact, that of the agents which in the inorganic kingdom bring about these changes, the imponderable principles are pre-eminent. I transfer this observation to the case of organized beings, and infer that the ner- 
vous system has the power of throwing organized atoms into the active or passive state; that this is the fundamental fact on which all the laws of interstitial death depend; and that upon this principle-its existing allotropic condition-an organized molecule either submits to the oxidizing influence of arterial blood, or successfully resists that action.

But it has been stated that there are certain pathological conditions, which, upon these views, meet with a clear explanation; conditions, which, though long and laboriously studied by physicians, remain involved in contradictions and obscurity. 'The conditions to which $I$ refer are those known as inflammation and congestion.

It is agreed among chemists, that during the prevalence of these conditions the urine assumes a peculiar constitution. In inflammatory actions the relative quantity of urea and sulphuric acid is much above the normal standard, whilst in congestive cases the reverse holds good, and the urea and sulphuric acid are below the standard. What is the interpretation of these remarkable facts? We shall find they are very significant.

The quantity of urea and sulphuric acid in the urine undoubtedly expresses the quantity of proteine matter that has undergone oxidation in the system. In all cases where that quantity is above the normal standard, the destruction of proteine matter has been correspondingly accelerated; and where it is deficient, the destruction has been reduced. The result of inflammations corresponds to the first of these cases, and of congestions to the second.

Recalling now what has been said respecting the cause of the capillary circulation, we see how all these apparently disconnected facts group themselves together in the attitude of dependent effects. In inflammation there has been that allotropic change in the soft solids involved, that they have assumed a disposition for rapid oxidation-they are active. Their relations with arterial blood have become highly exalted; and the blood flows, on the principles I have set forth, to the affected part with energy. Redness of that part and a higher temperature are the result. Oxidation goes on with promptitude, and urea and sulphuric acid begin to accumulate in the urine.

But in congestive cases it is the reverse; the parts affected are thrown into a more passive state. Oxidation goes on in a reluctant way, the amount of tissue metamorphosed diminishes, the urea and sulphuric acid diminish in the urine; and on the principles which I have endeavoured to explain respecting the capillary circulation, we perceive that an immediate 
action nust be exerted on the flow of the blood, the passive condition of the tissues and diminished capacity for oxidation restrain the flow from the arteries, and there being now less pressure on the contents of the veins, engorgement of those vessels is the result, and this condition of things is what a physician designates as congestion.

In this manner, if we admit the existence of allotropism in organic atoms, we can give a very clear explanation of the condition of the circulation in the pathological states of inflammation and congestion, and also of the peculiarities which in those states belong to the constitution of the urine.

University of New York,

Feb. 17, 1849.

XXXIV. On the discovery of the Chilling Process in the casting of the Specula for Reflecting Telescopes, \&.c. By Professor Potten, A.M., F.C.P.S., late Fellow of Queen's College, Cambridge.

To the Editors of the Philosophical Magazine and Journal. Gentuemen,

T PERCEIVE at page 143 of the February Number, that 1 in an abstract of a paper by Mr. Lassell read at the Astronomical Society on the 8th of December 1848, there is the following passage :- "The mode of casting the large speculum which I employed involved the principle, discovered, I believe, and first published, by Lord Rosse, of casting the speculum on what is technically called a chill, $i . e$. an iron base, slightly warmed, which causes the speculum to cool upwards in horizontal strata."

Your readers will find in the fourth volume of the new series of the Edinburgh Journal of Science, namely for 1831, that in a paper on improvements in the casting, working, \&c. of Specula for Reflecting Telescopes, I had discovered and there published (page 18) the improvement in speculum metal by casting upon a chilling surface.

All known substances which were affected in different manners by rapid and slow cooling, after being heated, had up to that time indicated that it was a general law, that sudden cooling induced the property of brittleness or loss of tenacity, cracking, and frequent falling into fragments of the substance suddenly cooled; and that the opposite procedure of very slow and gradual cooling, which was generally called annealing, induced toughness and tenacity in the substance. Glass, many minerals, and steel, were known to be subject to this law. 